Lell, H. M.. Las palabras de la ley y la interpretación normativa. El clásico problema del derecho y el lenguaje. Derecho y Ciencias Sociales. Octubre 2017. No 17. Pgs 164-184 ISNN 1852-2971. Instituto de Cultura Jurídica y Maestría en Sociología Jurídica. FCJ y S. UNLP

\title{
Las palabras de la ley y la interpretación normativa. El clásico problema del Derecho y el lenguaje
}

\author{
The words of the legal rules and normative interpretation. The classical issue of Law and \\ language
}

Helga María Lell ${ }^{\bullet}$

\section{Resumen}

Si bien el reemplazo del Código Civil ha aparejado diversos cambios, una cuestión en común en ambos es la remisión a las palabras de la ley en materia de interpretación. Con este punto de partida, este trabajo pretende realizar una breve enunciación de múltiples jusfilósofos que se han abocado a alguna arista de la relación entre Derecho y lenguaje como forma de dar cuenta de que la misma determinación de qué implica el vínculo antedicho es una tarea dificultosa e interminable. En segundo término, se exponen algunos inconvenientes linguísticos que surgen de la utilización del lenguaje por parte del Derecho.

Este artículo constituye un avance de investigación y parte de una metodología cualitativa, descriptiva y con énfasis en las discusiones teóricas. Si bien no se presentan resultados, se pretende sintetizar en estas páginas la enorme complejidad de los problemas de la relación lenguaje-Derecho-interpretación.

Palabras clave: Interpretación, lenguaje, normas, problemas lingüísticos

\begin{abstract}
Despite the replacement of the Argentinian Civil Code has brought different changes, there is a matter that both have in common and it is the remission to the words of the legal rules. Under this frame, this article aims to present different legal philosophers that have approached to the relation between Law and language as a way to show how complicated and endless are the discussions about it. In second term, we present some linguistic problems that emerge from the utilization of language by law.

This work is part of a research and has a qualitative and descriptive methodology. We do not present results here and we only try to present how complex the problems of the relation between language, law and interpretation are.
\end{abstract}

Key words: Interpretation - language - legal rules - lingüistic problems

\footnotetext{
- Becaria podoctoral (Conicet). Doctora en Derecho (Universidad Austral), Especialista y Maestranda en Estudios Sociales y Culturales (UNLPam), Maestranda en Filosofía (UNQ). Docente de la Facultad de Ciencias Económicas y Jurídicas (UNLPam). Correo: hlell@ius.austral.edu.ar
}

Recibido: 1/03/2017 . Aceptado: 29/6/2017 
Lell, H. M.. Las palabras de la ley y la interpretación normativa. El clásico problema del derecho y el lenguaje. Derecho y Ciencias Sociales. Octubre 2017. No 17. Pgs 164-184 ISNN 1852-2971. Instituto de Cultura Jurídica y Maestría en Sociología Jurídica. FCJ y S. UNLP

\section{Las palabras de la ley y la interpretación normativa. El clásico problema del Derecho y el lenguaje}

Helga Lell

\section{Introducción}

El nuevo Código Civil y Comercial de la Nación argentina, que entró en vigencia en el curso del año 2015, introdujo una serie de modificaciones en relación con la normativa anterior. Uno de estos cambios se refleja en el artículo 2, destinado a la interpretación. La legislación de Vélez Sarsfield, si bien tenía un precepto muy semejante en su artículo 16, parecía dar menos lugar a las dudas en el proceso hermenéutico. A pesar de las diferencias entre uno y otro, hay semejanzas. Una coincidencia es la remisión a las palabras de la ley como primer elemento a tener en cuenta en la interpretación. La forma en que aparece esta idea en ambos códigos hace pensar que es muy simple recurrir a la literalidad de la normativa. No obstante, la relación entre lenguaje y Derecho es cualquier cosa menos sencilla. De hecho, es tan compleja que hasta hay innumerables consideraciones y enfoques acerca de qué inconvenientes y ventajas surgen de este vínculo.

En este marco, este trabajo pretende realizar una breve enunciación de múltiples jusfilósofos que se han abocado a alguna arista de esta relación, como forma de dar cuenta de que la misma determinación de qué implica el vínculo antedicho es una tarea dificultosa e interminable. En segundo término, se exponen algunos inconvenientes lingüísticos que surgen de la utilización del lenguaje por parte del Derecho.

Como puede notarse, este trabajo constituye un avance de investigación y parte de una metodología cualitativa, descriptiva y con énfasis en las discusiones teóricas. Si bien no se presentan resultados, se pretende sintetizar en estas páginas la enorme complejidad de los problemas de la relación lenguaje-Derecho-interpretación.

\section{Algunas investigaciones sobre la relación entre Derecho y lenguaje}

La relación entre el Derecho y el lenguaje en sus múltiples y variadas dimensiones ha sido tema de preocupación de muchos pensadores y a ella se le ha dedicado un sinfín de trabajos. 
Lell, H. M.. Las palabras de la ley y la interpretación normativa. El clásico problema del derecho y el lenguaje. Derecho y Ciencias Sociales. Octubre 2017. No 17. Pgs 164-184 ISNN 1852-2971. Instituto de Cultura Jurídica y Maestría en Sociología Jurídica. FCJ y S. UNLP

A solo título ejemplificativo, dentro de las publicaciones que se han preocupado por la relación entre Derecho y lenguaje, disciplina jurídica y lingüística, sistemas de normas y lenguas, actos jurídicos y actos de habla, discurso jurídico, interpretación jurídica a partir de métodos lingüísticos, entre otros, se pueden traer a colación algunos autores y corrientes. Esta enumeración es extremadamente incompleta pero tiene como finalidad mostrar que, a pesar de efectuar un pequeñísimo recuento, puede notarse la gran cantidad de obras que se han dedicado a este tópico. Por otro lado, puede verse que los trabajos que se mencionan difieren entre sí y, por lo tanto, dan cuenta de lo interminable de la consideración de este vínculo.

En su reflexión acerca de los aportes mutuos entre la Lingüística y el Derecho en los ámbitos quebequense, francés y polaco, en donde han tenido un gran auge, Gałuskina (2012) menciona que la Lingüística del Derecho es una denominación genérica que engloba los diferentes aspectos del análisis lingüístico del Derecho y de la reflexión lingüística alimentada por el fenómeno jurídico. Estos estudios constituyen un dominio interdisciplinario que combinan los variados enfoques de las ciencias del lenguaje y del Derecho y parten de la relevancia del uso de las lenguas en la construcción de los distintos sistemas jurídicos dado que 1) existe un lenguaje jurídico específico (en contraposición con el lenguaje natural); 2) es parte de la naturaleza jurídica el interpretar las normas jurídicas; 3) porque el fenómeno jurídico implica un acto de comunicación. Como señala, la atención concentrada en la utilización de la Lingüística se desarrolló sobre todo a partir de la década de 1970, con el auge de esta disciplina por sobre las demás ciencias sociales. El campo de las aplicaciones en las que la coordinación de los esfuerzos de ambas disciplinas posee utilidad es amplio, desde la elaboración legislativa, la traducción normativa, la lingüística forense, concentrada en el análisis probatorio y la calificación de hechos en el marco de procesos judiciales, etc.

Una famosa obra, medianamente reciente (la primera edición data de 1990, la última de 2005), elaborada por Cornu, señala que la Linguiística jurídica es el estudio del sentido y la forma de las palabras en las que se realiza el Derecho y constituye una herramienta auxiliar de la elaboración y de la interpretación normativas. Entre las preocupaciones de estos análisis interdisciplinarios se destaca aquella respecto de si la accesibilidad del Derecho requiere la comprensión por parte de todos los ciudadanos de los textos jurídicos, portadores de un vocabulario específico y técnico. En torno a ello, el autor plantea la necesidad de determinar el vocabulario jurídico, de distinguir el lenguaje natural del 
Lell, H. M.. Las palabras de la ley y la interpretación normativa. El clásico problema del derecho y el lenguaje. Derecho y Ciencias Sociales. Octubre 2017. No 17. Pgs 164-184 ISNN 1852-2971. Instituto de Cultura Jurídica y Maestría en Sociología Jurídica. FCJ y S. UNLP

jurídico, de circunscribir expresiones, de evitar la polisemia y de analizar los sentidos que puedan ser atribuidos a las notions-cadres (esto es, los conceptos jurídicos indeterminados), entre otros. Asimismo, define al discurso jurídico como la puesta en juego de la lengua por el habla al servicio del Derecho, y que es al mismo tiempo un acto lingüístico y un acto jurídico. La puesta en práctica de este discurso pone en marcha diversos tipos de análisis, por ejemplo, quiénes son los sujetos del discurso, de qué tipo de discurso se trata, qué tipo de mensaje porta, entre otros. En este marco, Cornu distingue cuatro tipos de discurso jurídico: el legislativo, el jurisdiccional, el consuetudinario y la expresión corporal en el lenguaje del derecho (ver Cornu, 2005).

Estos análisis de Cornu son citados por CiuroCaldani (2009 y 2011a y b) quien, en el ámbito argentino, ha publicado algunos artículos en relación con la aplicación a las normas jurídicas de las categorías del jurista francés.

Desde la mirada del realismo escandinavo, Olivecrona (2010) sostiene que el lenguaje jurídico es una parte del lenguaje corriente y, en cuanto a los hechos, apunta la necesidad de que estos se adapten a los conceptos de deber y al de derecho y no viceversa, dado que resalta el carácter realizativo de los enunciados jurídicos.

En el intento de aplicar su teoría de la acción comunicativa al campo jurídico, Habermas(2005) propone una relación diferente entre el Derecho y el discurso. Ello dado que acentúa la moral procedimental en la formación del Derecho y señala que el principio de validez es el principio del discurso según el cual merecen ser válidas solamente las normas que pudieran encontrar la aprobación de todos los potencialmente interesados en la medida en la que participan en discursos racionales.

Concentrado en la interpretación jurídica, Aarnio(1987, 1990 y 1991) sostiene que en las complejas sociedades occidentales actuales, una misma norma jurídica puede recibir interpretaciones múltiples sin que una sea más correcta que las otras desde un punto de vista sustantivo. Ello no deriva en un escepticismo o en un relativismo total sino que el jurista escandinavo señala que la corrección de las respuestas depende de la posibilidad de justificar racionalmente una postura frente a un auditorio conforme a ciertos parámetros sociales.

Al seguir los desarrollos de la tradición polaca en torno a la Linguiística jurídica, Wróblewski(1985/1988 y 1989) (aunque no solo él, sino también muchos otros juristas) distingue el discurso en el que se formulan las leyes de aquel en el que se habla de las 
Lell, H. M.. Las palabras de la ley y la interpretación normativa. El clásico problema del derecho y el lenguaje. Derecho y Ciencias Sociales. Octubre 2017. No 17. Pgs 164-184 ISNN 1852-2971. Instituto de Cultura Jurídica y Maestría en Sociología Jurídica. FCJ y S. UNLP

leyes. El primero es el lenguaje legal. El segundo, el lenguaje del Derecho, es un metalenguaje e incluye tres subtipos: el lenguaje jurídico jurisprudencial, el lenguaje jurídico científico y el lenguaje jurídico común. Asimismo, resulta una preocupación de este jurista la pregunta por la relación con el lenguaje natural. Desde otra perspectiva, en lo que a la interpretación jurídica y constitucional se refiere, entre los contextos, este jusfilósofo polaco menciona el lingüístico en relación con los aspectos sintácticos, semánticos y pragmáticos del lenguaje jurídico.

Otro polaco, pero focalizado en el aspecto lógico del Derecho, Kalinowski (1985), entiende que las normas jurídicas tienen como referencia ciertas estructuras deónticas de la realidad y una semántica realista completa de estas debe distinguir entre la significación (función de los signos lingüísticos en relación con el pensamiento) y la designación (función de un muchos signos lingüísticos en relación con los entes reales) y no perder de vista alguna de ellas. Ello en tanto no hay designación sin significación aunque la última puede darse sin la primera. Sobre la función significativa de las expresiones normativas, ellas significan proposiciones normativas que dirigen al hombre y normativizan su conducta. En cuanto a la designación, las normas jurídicas designan un estado de cosas real, una relación normativa de obligación activa de hacer, de abstenerse o de permisión ${ }^{1}$.

Moore (2001) propone realizar un análisis de la extensión con la que la Constitución debería ser interpretada para ampliar la versión mínima de las aspiraciones para una buena sociedad. Esta propuesta deriva en la idea de que los jueces deberían realizar una gran tarea de teorización moral en la interpretación de las cláusulas constitucionales que confieren derechos. Además, afirma, esta labor es perfectamente consistente con la obligación de fidelidad constitucional gracias al derecho natural o a la teoría realista de la interpretación constitucional. Esta última es un conjunto de pasos generales que describen las características para la determinación de una buena decisión jurídica a la luz de un texto legal. Sin embargo, Moore no se interesa primordialmente en los pasos hacia la decisión, sino más bien por lo que hace a una decisión correcta. Por ello, se centra en los significados de las palabras y oraciones que conforman las pautas constitucionales y propone como modo de develarlos la concepción semántica realista. Según esta, el

\footnotetext{
${ }^{1}$ Existen múltiples trabajos que conforman la concepción de Kalinowski acerca de la semántica normativa que aquí no se citan. No obstante, para ampliar acerca de la obra de este jurista polaco en torno al tema, ver Massini Correas, 1993.
} 
Lell, H. M.. Las palabras de la ley y la interpretación normativa. El clásico problema del derecho y el lenguaje. Derecho y Ciencias Sociales. Octubre 2017. No 17. Pgs 164-184 ISNN 1852-2971. Instituto de Cultura Jurídica y Maestría en Sociología Jurídica. FCJ y S. UNLP

referente de un signo (que es un factor extra-lingüístico) determina su sentido y no el conjunto de características que forman su designación. Entonces, la denotación no responde a una propiedad social o comunidad de hablantes sino que responde a la naturaleza de lo designado. El significado se encuentra en los hechos y no en la comunicación.

Para Dworkin(1988) existe un conjunto de teorías, entre ellas la de Hart, que padecen de un "aguijón semántico" dado que insisten en que todos los juristas siguen un cierto criterio lingüístico para juzgar proposiciones jurídicas. Este inconveniente consiste en no poder explicar desacuerdos teóricos en la práctica jurídica por pensar que los juristas comparten tests incontrovertibles acerca de la verdad de las proposiciones jurídicas (Endicott, 2002).

Por su parte, Carrió ha sido uno de los principales juristas argentinos en preocuparse por la relación entre el lenguaje y el Derecho a partir de la exposición de que el lenguaje con el que se formula el fenómeno jurídico es el natural y ello acarrea algunos inconvenientes. A partir de este disparador, este jurista explicita algunos problemas propios de la naturalidad del lenguaje y su influencia en la interpretación jurídica. Esta exposición ha sido fuertemente criticada por $S_{0 l e{ }^{2}}$, partidario de la tecnificación máxima de los términos legales, lo cual dio lugar a las respectivas réplicas del jusfilósofo observado ${ }^{3}$.

También desde una perspectiva positivista, Vernengo (1994a y b) afirma la relación entre Derecho y lenguaje aunque no cree que pueda sostenerse que el primero consiste en el segundo. Asimismo, se ha abocado a los diferentes problemas lingüísticos propios de la interpretación literal de la ley y también ha criticado fuertemente la definición de lo jurídico como discurso.

En el marco de la escuela crítica, Entelman, Marí, Cárcova, Ruiz, Duquelsky, entre muchos otros, han analizado al Derecho como un discurso productor de efectos en torno a la legitimidad del poder, a las ideologías políticas y a la construcción de subjetividades ${ }^{4}$. En la misma corriente, Aseff (1998 y 2003) se ha abocado a conjugar la teoría de la

\footnotetext{
${ }^{2}$ Las críticas de Soler a Carrió y su posición respecto del lenguaje del Derecho constan en Soler, Sebastián. Las palabras de la ley. Veracruz: Praxis Jurídica, 1974.

${ }^{3}$ La obra que concentra los distintos desarrollos de Carrió es Carrió, 1990/1994. En ella se encuentran, en sus sucesivas ediciones, diferentes perspectivas acerca de la relación entre el Derecho y el lenguaje. No obstante, también se han publicado trabajos independientes que son parte de esta obra. Ver Carrió, 1971; Carrió, 2008

${ }^{4}$ A simple título ejemplificativo se pueden mencionar obras como: Entelman, 1982; Ruiz, 2003; Cárcova, 2006; Cárcova, 2009, Legendre, Entelman, Kozicki, Abraham, Marí, Le Roy y Vezzetti, 1982.
} 
Lell, H. M.. Las palabras de la ley y la interpretación normativa. El clásico problema del derecho y el lenguaje. Derecho y Ciencias Sociales. Octubre 2017. No 17. Pgs 164-184 ISNN 1852-2971. Instituto de Cultura Jurídica y Maestría en Sociología Jurídica. FCJ y S. UNLP

argumentación con los avances del análisis crítico del discurso, principalmente a partir de los desarrollos de van Dijk y Verón.

Al referirse a la actividad interpretativa del quehacer judicial, Zambrano (2009a y b) señala que la inevitable creatividad que caracteriza dicha tarea se sitúa en un campo acotado entre un margen inferior, dado por las reglas de la lingüística, y un margen superior, establecido por principios morales objetivamente reconocibles como tales. La primera $-\mathrm{y}$ que interesa aquí- ocurre porque el Derecho no puede regular en forma general si carece de la potencialidad para ser leído en forma sustancialmente igual por el público general al que se propone obligar. "Si cada intérprete sólo reproduce sus propios pre-conceptos cada vez que determina el sentido de las normas, entonces el derecho sería una farsa inútil" (Zambrano, 2009b: 65). Asimismo, esta jusfilósofa aborda los aspectos discursivos y pragmáticos del discurso jurídico y señala la necesidad de considerar los fines del Derecho para llevar a cabo una interpretación propiamente jurídica y comprender el obrar humano. Al respecto, explicita como complejidad que las normas jurídicas son el resultado de actos de habla de órganos colegiados, institucionales y textuales y, por ello, su interpretación requiere la dilucidación de las intenciones de los autores, de las "autoridades de las autoridades" y de un conjunto de actores relevantes en contextos no inmediatos al de enunciación.

En sus estudios de posgrado, Del Carril (2007) ha trabajado en el establecimiento de pautas racionales para lograr cierta uniformidad en los métodos de asignación de un sentido válido a las palabras que utilizan los jueces. Para ello realiza una presentación de los problemas lingüísticos con los que se enfrentan los juristas y, en particular, los intérpretes de los enunciados jurídicos; además, se aboca a la presentación del uso semántico en la argumentación judicial ${ }^{5}$.

Por otro lado, gran parte de la atención en el ámbito jurídico ha sido captada por el análisis de tipo pragmático, sobre todo a partir de los estudios de Austin y Searle ${ }^{6}$.

Asimismo, una investigación que constituye una referencia obligada es la de Pardo (1992) que, con una mirada propia desde su formación en Lingüística, se enfoca en el análisis de sentencias judiciales. En su trabajo presenta a los textos jurídicos a partir de diferentes

\footnotetext{
${ }^{5}$ Ver Del Carril, Enrique. El lenguaje de los jueces. Criterios para la delimitación de significados lingüísticos en el razonamiento judicial. Buenos Aires: Ad-Hoc, 2007.

${ }^{6}$ Ver Austin, 1971 y Searle, 1986. Dos ejemplos de este tipo de análisis (de entre una amplia multiplicidad) son: Casagrande, 2011. y López Hernández, 2005.
} 
Lell, H. M.. Las palabras de la ley y la interpretación normativa. El clásico problema del derecho y el lenguaje. Derecho y Ciencias Sociales. Octubre 2017. No 17. Pgs 164-184 ISNN 1852-2971. Instituto de Cultura Jurídica y Maestría en Sociología Jurídica. FCJ y S. UNLP

clasificaciones y analiza los distintos elementos que confluyen a su composición discursiva.

Desde el Centro de Investigaciones en Derecho y Linguiística de la Facultad de Derecho de la Universidad Nacional de Rosario, Álvarez (2000, 2008a y b) y su equipo se concentran en el análisis del discurso jurídico y en las técnicas de expresión oral y escrita en las distintas incumbencias profesionales de los abogados. Esta lingüista considera que la referencia al discurso jurídico conlleva la distinción entre 1) el discurso normativo, que es el propio de la redacción de las leyes y es el objeto de estudio de la técnica legislativa o ciencia de la legislación; 2) el discurso parlamentario, que se desarrolla en el seno del Poder Legislativo, donde los enunciadores poseen normas específicas para hacer uso del habla y que, cuando lo hacen, presentan argumentos para defender o refutar la sanción de las leyes; 3 ) el discurso forense o judicial que es aquel que se produce en el ámbito de la administración de justicia, abarca el discurso de las partes y los fallos o sentencias, que constituyen el discurso de poder institucionalizado del campo de la Justicia.

Otros ejemplos de manifestación del interés por la concurrencia interdisciplinaria entre el Derecho y la Lingüística en el ámbito académico argentino, con un mayor acento en la segunda, lo constituyen los trabajos de: Narvaja de Arnoux (2006) ${ }^{7}$ enfocados en el análisis del discurso en general, pero con incursiones en el campo jurídico; y los de Vasilachis de Gialdino (2013), con una propuesta que agrega a la Sociología como tercer campo en concurrencia. En La Plata, Cuccato (2012 y 2013) y su grupo interdisciplinario de investigación, lleva a cabo el análisis del discurso jurídico judicial con enfoque en determinadas expresiones y en la pragmática de ciertos actos jurídicos; entre muchos otros juristas y lingüistas.

Como puede notarse, la enumeración realizada, aunque no exhaustiva, revela que la relación entre Lenguaje y Derecho ha sido foco de atracción para juristas, lingüistas y filósofos desde los más diversos enfoques y ha dado lugar a múltiples interrogantes y respuestas. Aun así, faltan trabajos de renombrados autores, tales como Massini Correas (1988), Sourioux y Lerat (1975), Iturralde Sesma (2014), Guarinoni (2006), Viola y Zaccaría (2007), Streck (1999 y 2008), Guibourg (2002 y 2011), Bobbio (1950), Capella (1968), Conte (2000), Duarte y Martínez (1995), Gómez y Bruera (1984/2000), Bielsa

\footnotetext{
${ }^{7}$ Ver en particular en el capítulo 1 "El análisis del discurso como campo interdisciplinario", el apartado "A modo de ilustración: un caso jurídico”, pp. 23-29.
} 
Lell, H. M.. Las palabras de la ley y la interpretación normativa. El clásico problema del derecho y el lenguaje. Derecho y Ciencias Sociales. Octubre 2017. No 17. Pgs 164-184 ISNN 1852-2971. Instituto de Cultura Jurídica y Maestría en Sociología Jurídica. FCJ y S. UNLP

(1954), García Marcos (2004), Hernández (2009), Marmor (2001), entre tantos otros. La selección de juristas ha resultado casi azarosa dado que no es representativa del vasto campo de publicaciones al respecto. Por supuesto, restaría mencionar un sinfín de trabajos que son relevantes pero un análisis de cada uno de ellos escapa al objeto y posibilidades de este artículo.

\section{Las palabras de la ley}

El Código Civil argentino hoy derogado, en su artículo 16 señalaba: "Si una cuestión civil no puede resolverse, ni por las palabras, ni por el espíritu de la ley, se atenderá a los principios de leyes análogas; y si aún la cuestión fuere dudosa, se resolverá por los principios generales del derecho, teniendo en consideración las circunstancias del caso". Esta redacción deja entrever que, para interpretar una norma jurídica a aplicarse a un caso concreto, podría ser suficiente el recurso a las palabras con las que se ha formulado una prescripción y al espíritu del legislador. Subsidiariamente, si ni uno ni otro recurso han arrojado claridad sobre el sentido normativo, entonces, y solo entonces, el Código de Vélez Sarsfield permitía echar mano de otras herramientas hermenéuticas complementarias.

El actual Código Civil y Comercial, en su artículo 2, preceptúa: “Interpretación. La ley debe ser interpretada teniendo en cuenta sus palabras, sus finalidades, las leyes análogas, las disposiciones que surgen de los tratados sobre derechos humanos, los principios y los valores jurídicos, de modo coherente con todo el ordenamiento".

La coincidencia en ambos códigos de la remisión a las palabras de la ley parece una cuestión lógica puesto que las normas, al ser mensajes a comunicarse, requieren, necesariamente de su formulación en lenguaje (von Wright, 1971). En lo natural de esta situación y en lo cotidiano de esta forma de comunicar e interpretar las normas, existen algunos tópicos que es interesante recordar o resaltar. El hecho de que las normas jurídicas se nutran del lenguaje implica observar, en primer lugar, la relación entre las formulaciones y el lenguaje común y el técnico-jurídico. Esto, que pareciera no demasiado complejo, puede ofrecer algunas complicaciones cuando se presentan ambigüedades, vaguedades, etc. Por otro lado, interpretar las palabras de la ley tiene efectos sobre los cuales caben algunas preocupaciones jurídicas. Sobre estas cuestiones, tratan los siguientes apartados. 
Lell, H. M.. Las palabras de la ley y la interpretación normativa. El clásico problema del derecho y el lenguaje. Derecho y Ciencias Sociales. Octubre 2017. No 17. Pgs 164-184 ISNN 1852-2971. Instituto de Cultura Jurídica y Maestría en Sociología Jurídica. FCJ y S. UNLP

\section{La interpretación jurídica y sus problemas ${ }^{8}$}

Si bien las temáticas de la relación del lenguaje y el derecho, por un lado, y la interpretación jurídica, por el otro, son distintas e independientes, existen múltiples puntos de contacto entre ellas. En particular, en este artículo se parte de la concepción del Código Civil y Comercial argentino sobre la interpretación y el recurso a las palabras de la ley. Por este motivo, aquí me permito introducir algunas complejidades hermenéuticas antes de retomar los problemas entre derecho y lenguaje.

Señala Mendonca (2000) que hablar de interpretación no es una cuestión tan sencilla como suele parecer ya que dicho término padece de una ambigüedad de proceso-producto: con él se hace alusión tanto a la actividad de desentrañamiento como al resultado de ella, es decir, al sentido obtenido o creado (según se crea que la actividad interpretativa es descriptiva o creativa).

De acuerdo con una manera extendida de hablar, las nomas son objeto de interpretación, pero esto solo es correcto si por "norma" se entiende una formulación normativa. Ese modo de hablar es incorrecto, por el contrario, si por "norma" se entiende su contenido significativo. En este último caso, la norma no constituye el objeto de la interpretación, sino el producto de la actividad interpretativa.

En este marco, el significado de las formulaciones normativas está determinado por el significado de las palabras que la integran y por el orden sintáctico de ellas. Frecuentemente, las palabras que componen las formulaciones normativas plantean problemas en cuanto a la determinación de su significado, en otras el vínculo sintáctico entre los términos de la formulación da lugar a equívocos. De ello se sigue que no siempre sea sencillo determinar qué norma es expresada por una formulación normativa.

Los problemas que corrientemente son señalados por los teóricos generales del derecho y que afectan al lenguaje normativo son la ambigüedad, la vaguedad y la textura abierta del lenguaje.

La ambigüedad implica que una formulación normativa o un término dentro de ella cuando, en un contexto dado, sea posible asignarle dos o más significados. En el caso de la ambigüedad de las formulaciones normativas, se produce que el intérprete deba elegir entre dos normas.

\footnotetext{
${ }^{8}$ En este apartado se sigue a Mendonca, 2000 y Suárez, 2009.
} 
Lell, H. M.. Las palabras de la ley y la interpretación normativa. El clásico problema del derecho y el lenguaje. Derecho y Ciencias Sociales. Octubre 2017. No 17. Pgs 164-184 ISNN 1852-2971. Instituto de Cultura Jurídica y Maestría en Sociología Jurídica. FCJ y S. UNLP

Un ejemplo focalizado en un término ambiguo es la palabra "sostiene" que aparece en el artículo $2^{\circ}$ de la Constitución Nacional argentina cuando señala que el Estado sostiene al culto católico apostólico y romano. La inclusión de esta palabra allí ha dado lugar a variadas discusiones acerca de la extensión de la obligación estatal (¿debe el Estado profesar el culto o asistirlo económicamente?) (Suárez, 2009).

Otro caso es el del artículo 59, inciso g) del Código Civil y Comercial argentino, aparece la palabra "vital" al señalar la posibilidad, por parte de un enfermo terminal, de rechazar medidas de soporte vital ${ }^{9}$. No obstante, vital puede ser entendido, según la RAE (2014), como algo relativo a la vida (en este caso, si se retira el soporte, el paciente, indefectiblemente, morirá), como algo que hace alusión a una gran energía o impulso de vivir (en este caso, podría ser desechar un objetivo relevante para el paciente), o algo de suma relevancia o trascendencia (en este caso, podría ser retirar un calmante, medida que, aunque no lo matará, sí le generará un enorme sufrimiento a causa de dolores insoportables). Este ejemplo de múltiples significados de una palabra y que repercute en brindar diferentes sentidos a una norma, es de ambigüedad semántica.

Otro tipo especial de ambigüedad que destaca Suárez (2009) es, no el que afecta a una sola palabra, sino el que cambia el sentido de un enunciado por problemas sintácticos o de orden de los elementos de la oración. El autor postula el siguiente ejemplo: el artículo 44 del viejo Código Civil disponía que "las personas jurídicas nacionales o extranjeras tienen su domicilio en el lugar en que se hallaren, o donde funcionen sus direcciones o administraciones principales, no siendo el caso de competencia especial". En esta norma jurídica, la coma ubicada después de "hallaren" da a entender que las personas jurídicas pueden tener lugar donde se hallen y, por lo tanto, que podrían ser ambulantes (algo que no es asî). Si eliminamos la respectiva coma, la interpretación da lugar a comprender que se refiere a que el domicilio coincide con el lugar en donde se hallen sus direcciones o administraciones principales.

Una oración puede ser ambigua porque contiene palabras ambiguas (en este caso, la ambigüedad es semántica) pero también porque el orden en el que aparecen los términos causan este problema (ambigüedad sintáctica) (Mendonca, 2000).

\footnotetext{
${ }^{9}$ Mendonca (2000) trae a colación ejemplos similares para ambos tipos de ambigüedad y para los casos de vaguedad con el ordenamiento jurídico español.
} 
Lell, H. M.. Las palabras de la ley y la interpretación normativa. El clásico problema del derecho y el lenguaje. Derecho y Ciencias Sociales. Octubre 2017. No 17. Pgs 164-184 ISNN 1852-2971. Instituto de Cultura Jurídica y Maestría en Sociología Jurídica. FCJ y S. UNLP

Otro ejemplo de ambigüedad sintáctica es el siguiente: el Código Civil y Comercial argentino, en su artículo 744, inciso a), menciona que quedan excluidos de ser bienes de garantía "las ropas y muebles de uso indispensable del deudor, de su cónyuge o conviviente, y de sus hijos”. El uso indispensable ¿constituye un requisito que califica solo a los muebles o tanto a los muebles como a las ropas?

En cuanto a la vaguedad, esta afecta a los conceptos y no permite identificar con claridad la extensión del campo semántico. Por ejemplo, si pensamos en la alevosía con la cual se puede cometer un homicidio: ¿a partir de cuántas puñaladas estamos frente a un homicidio agravado y no ante un homicidio simple? O si pensamos en el escalamiento, también en la esfera penal, ¿cuál es la altura adecuada para señalar que alguien se ha esforzado en escalar: un metro, dos metros? ¿Incide en algo la altura de la persona, es decir, alguien muy bajo realiza el mismo esfuerzo que alguien muy alto en un muro de un metro?

Mendonca (2000) destaca diferentes tipos de vaguedad:

-de graduación: en ella no existe un límite preciso entre la aplicabilidad y la inaplicabilidad de una palabra. En este supuesto, la palabra es claramente aplicable a ciertas situaciones, pero no en otras. Ejemplos de ella son las palabras polares: alto/bajo, flaco/gordo, lento/rápido, aburrido/divertido, etc.

-de combinación: en ella no existe un conjunto definido de condiciones que gobierne la aplicación de la palabra ya sea porque no hay un conjunto limitado y necesario para saber cuándo se da el supuesto o porque es imposible enumerar la totalidad de las características necesarias. Ejemplos de ello son "buena fe", "ensañamiento", "tratos dignos", "formato adecuado", etc.

-de indeterminación: ella acaece por la falta de especificación acerca de alguna cuestión relevante relativa al contenido significativo de la formulación interpretada como la individuación del destinatario, la especificación de la ocasión en la que debe ejecutarse la acción regulada o alguna otra circunstancia. Por ejemplo, en el anterior Código Civil argentino, hasta la reforma de 1968, la fijación de la legítima establecida por el artículo 3602, se debía realizar atendiendo "al valor de los bienes quedados por muerte del testador". Hasta la reforma antedicha, se debatía en relación a qué momento debía hacerse la valuación: si al momento del deceso, del reparto de la legítima, del día de hacerse la valuación, etc. 
Lell, H. M.. Las palabras de la ley y la interpretación normativa. El clásico problema del derecho y el lenguaje. Derecho y Ciencias Sociales. Octubre 2017. No 17. Pgs 164-184 ISNN 1852-2971. Instituto de Cultura Jurídica y Maestría en Sociología Jurídica. FCJ y S. UNLP

-de anomalía semántica: en este caso, si bien la formulación pareciera gramaticalmente correcta, se produce un sinsentido. Mendonca (2000: 162) explica que la Constitución paraguaya señala "Esta Constitución no perderá su vigencia ni dejará de observarse por actos de fuerza o fuera derogada por cualquier otro medio distinto del que ella dispone". El problema, menciona este autor, surge de una ligera alteración: donde dice "ni dejará", debe decir "si dejara".

-de bivalencia: en virtud de que los operadores jurídicos trabajan con un lenguaje que corre entre dos vías, esto es, el lenguaje común, natural o cotidiano y el lenguaje técnico jurídico, se pueden producir diferentes significados. Esta cuestión es tratada más adelante en el apartado "Las palabras de la ley y los problemas lingüísticos".

Finalmente, la textura abierta del lenguaje, implica la posibilidad de que los términos adquieran nuevos significados con el transcurso del tiempo. Ejemplos de ello son términos como "vehículo" (hace doscientos años no hubiéramos pensado en los vehículos de la actualidad), "navegar" (inicialmente, este término se utilizaba para la navegación sobre agua. Hoy en día abarca también la aérea y hasta la cibernética). Sobre el final de este artículo, se brindan otros ejemplos relacionados con algunos avances tecnológicos.

\section{Las palabras de la ley y los problemas lingüísticos ${ }^{10}$}

Las normas jurídicas se elaboran a partir de las palabras. Una gran parte de dichas palabras pertenece al lenguaje común y, por lo tanto, comparten el sentido que tienen en este marco y los problemas lingüísticos. Otro conjunto de palabras son específicas y exclusivas del lenguaje técnico y, por lo tanto, su significado depende estrictamente del que le atribuyen los juristas; ejemplos de ello son "hipoteca", "enfiteusis", "anticresis", “abigeato", etc.

La cuestión es un poco más compleja si se observa que existen otros términos que son compartidos entre el lenguaje común y el técnico y que difieren en su campo semántico: prenda (no es lo mismo el derecho real que un artículo de vestir adquirido en un comercio o la sanción que se impone a quien pierde en un juego de niños), competencia (no es lo mismo la competencia de un juez como el ámbito, por ejemplo, territorial, en el cual puede actuar que una competencia futbolística), servidumbre (no es lo mismo el derecho real de

\footnotetext{
${ }^{10}$ En este apartado se sigue a Suárez, 2009 quien, además de postular estos problemas, incluye la serie de ejemplos que han sido traídos a colación aquí.
} 
Lell, H. M.. Las palabras de la ley y la interpretación normativa. El clásico problema del derecho y el lenguaje. Derecho y Ciencias Sociales. Octubre 2017. No 17. Pgs 164-184 ISNN 1852-2971. Instituto de Cultura Jurídica y Maestría en Sociología Jurídica. FCJ y S. UNLP

servidumbre que la servidumbre contratada por un empleador para la atención de una mansión).

Asimismo, hay casos que pertenecen tanto al lenguaje común como al técnico-jurídico y que poseen múltiples significados. Esta ambigüedad debe ser erradicada a partir de la evaluación del contexto de uso del término. Por ejemplo, la palabra "sanción" puede referirse al último paso correspondiente al Congreso en el marco del proceso de aprobación de un proyecto de ley, pero también puede significar el consecuente lógico que se le imputa a un acto ilícito. Otro caso es el de la palabra "prescripción" que permite pensar tanto en las normas que se elaboran con lenguaje y función prescriptiva como en la institución que libera a una persona de obligaciones o que le permite adquirir derechos a partir del transcurso del tiempo.

\section{Las palabras no correspondidas}

Otro problema que se presenta y no solo en el derecho es aquel que concierne a las posibilidades e imposibilidades de realizar traducciones adecuadas entre diferentes lenguas.

Por ejemplo, Guibourg, Ghigliani y Guarinoni (1986) destacan que, en castellano, utilizamos el término "reloj" para designar a los aparatos destinados a medir la hora. Sin embargo, en inglés se utiliza "clock" para el reloj de pared y "watch" para el de pulsera. En francés "horloge" designa el reloj de pared, "pendule" el de mesa y "montre" el de pulsera. Otros casos los señala Scavino quien menciona que los yamanas de Tierra del Fuego tienen un verbo para cosas que se rompen y cosas que se pierden. Cuando un animal muere dicen que se rompió, mientras que cuando una persona muere, dicen que se perdió. También recuerda las dificultades del español para traducir el "this" y el "that" del inglés, ya que, en el primer idioma, el sistema de demostrativos es ternario (este, ese, aquel) y no binario. A la inversa, donde en el español solo se puede señalar el genérico término de "libertad", los angloparlantes pueden ver "freedom" o "liberty" (Scavino, 2010). Luque Durán (2004) resalta que "llave" en español corresponde a "key", "faucet" y "wrench", mientras que "key" puede ser traducido por "llave", "clave" y "tecla". Asimismo, pone en evidencia que en inglés hay diferencias entre "dog" y "hound"; "sky" y "heaven"; "folk" y "town" y "time" y "weather", donde en el español se puede pensar en "perro", "cielo", "pueblo" y "tiempo". 
Lell, H. M.. Las palabras de la ley y la interpretación normativa. El clásico problema del derecho y el lenguaje. Derecho y Ciencias Sociales. Octubre 2017. № 17. Pgs 164-184 ISNN 1852-2971. Instituto de Cultura Jurídica y Maestría en Sociología Jurídica. FCJ y S. UNLP

El tema no es intrascendente en materia de derecho. Un caso se ha dado en la interpretación del artículo 86, inciso 2) del Código Penal de la Argentina que versa sobre la no punibilidad de los médicos que practican un aborto. Allí se menciona: "Si el embarazo proviene de una violación o de un atentado al pudor cometido sobre una mujer idiota o demente. En este caso, el consentimiento de su representante legal deberá ser requerido para el aborto". En virtud de la vaguedad de indeterminación que allí se presenta, la doctrina ha discutido si aquí se prevé el aborto sentimental (para cualquier tipo de violación) o solo el aborto eugenésico (solo para mujeres idiotas o dementes). Señala FontánBalestra (2002: 85-86): "El motivo de la inclusión inexplicable de los términos "atentado al pudor" parece ser el que Soler explica: en el Derecho alemán, cuya terminología siguió en esta parte el proyecto suizo, se denominaba técnicamente con vocablos distintos la violación cometida con violencia, a la que se designa como Notzucht, y la que se cumple con mujer idiota o alienada, a la que se califica de Schändung (...). En la versión alemana del proyecto suizo: los artículos 164: Notzucht, y 166: Schändung. A ambas se hacía referencia en el proyecto, en cuya versión francesa aparece la palabra Schändung traducida como attentatat à la pudeur d' une femme idiote, aliénée, inconsciente ouincapable de résistence. Al traducirse al castellano, las palabras "atentado al pudor" resultaron extrañas a la nomenclatura de nuestra ley, e incomprensibles si se utiliza una terminología puramente doctrinal. La misma inclusión de los casos de mujer inconsciente o incapaz de resistir, en el proyecto suizo, denota que se preveían allí las otras hipótesis del derogado art. 119 , inciso $2^{\circ}(\ldots)$ y por tanto también el aborto sentimental”.

\section{7- La textura abierta y la tecnología}

La textura abierta del lenguaje implica que un significante lingüístico puede llegar a abarcar en su campo semántico significados diferentes a los iníciales, es decir, el transcurso del tiempo modifica la denotación de un término. Saussure (1945) afirma que el transcurso del tiempo provoca una paradoja sobre el signo lingüístico porque, a la par que asegura su perdurabilidad, hace también a su mutabilidad. En este caso, el significante permanece y el significado varía.

En particular, en este apartado, interesa destacar un conjunto de ejemplos actuales que ha resaltado Battú en una ponencia y que se refieren al impacto de la tecnología en la redefinición semántica de algunos conceptos y su impronta jurídica. 
Lell, H. M.. Las palabras de la ley y la interpretación normativa. El clásico problema del derecho y el lenguaje. Derecho y Ciencias Sociales. Octubre 2017. No 17. Pgs 164-184 ISNN 1852-2971. Instituto de Cultura Jurídica y Maestría en Sociología Jurídica. FCJ y S. UNLP

El primer ejemplo al que se refiere la autora es el término "dopaje” y recuerda que, en el siglo pasado, este término implicaba a) administrar sustancias estimulantes para potenciar artificialmente el rendimiento del organismo con fines competitivos; b) introducir en un semiconductor impurezas con el fin de modificar su comportamiento. Esto conducía a que los controles antidoping se realizaran sobre personas físicas y animales que competían (como por ej. caballos y perros de carrera). Por lo tanto, las normas jurídicas hacían referencia a ellos. No obstante, esta autora trae a colación el caso del Tour de Francia 2016, en el cual también se realizó el control de máquinas (bicicletas). Señala, asimismo, que en la actualidad se habla de "dopaje tecnológico", "dopaje genético", "dopaje sanguíneo”, etc. “¿Implica "dopajetecnológico” el uso de trajes de baño de tela especial, que favorecen la movilidad de losnadadores en el agua? Movilidad del espacio semántico...” (Battú, 2016: 1).

El segundo ejemplo que presenta Battú es el caso de las frutas. Según un conjunto de normas, "Se entiende por fruta destinada al consumo, el fruto maduro procedente de la fructificaciónde una planta sana” (Artículo 887 - Resolución Conjunta SPReI N 169/2013 y SAGyP N²30/2013). Pregunta, entonces, la autora, qué ocurre cuando se inserta un gen animal en una fruta o verdura para mejorar su resistencia al clima o posibles plagas. “... las naranjas, papas ytomates resultantes ¿son incluidos en las normas jurídicas referentes a “frutos”? ¿Quéporcentaje de adn puede alterarse con genes de una especie diferente? ¿Se trata de un gruponuevo, pasible de reglamentación ad hoc?" (Battú, 2016: 1).

\section{8 - Consideraciones finales}

Este trabajo ha pretendido mostrar la complejidad y las múltiples discusiones en torno a los problemas del lenguaje y el derecho, por un lado, y por qué estos repercuten en la tarea interpretativa de los operadores jurídicos.

Si bien es usual oír hablar de la relación entre las palabras y las normas jurídicas, rara vez las explicaciones están acompañadas por una presentación profunda que dé cuenta de la gran multiplicidad de perspectivas desde las cuales se pueden aproximar o se han aproximado los teóricos a dicho vínculo. A efectos de mostrar quizás tan solo una pequeña arista de aquellos diversos enfoques, es que, en la primera parte de este artículo, se han mencionado diferentes autores y escuelas que se han abocado al tópico lenguaje y derecho. 
Lell, H. M.. Las palabras de la ley y la interpretación normativa. El clásico problema del derecho y el lenguaje. Derecho y Ciencias Sociales. Octubre 2017. No 17. Pgs 164-184 ISNN 1852-2971. Instituto de Cultura Jurídica y Maestría en Sociología Jurídica. FCJ y S. UNLP

En una segunda instancia, se ha presentado la remisión a las palabras de la ley que obra tanto en el Código Civil anterior como en el actual Código Civil y Comercial argentino y luego una serie de problemas lingüísticos o enunciativos. Estos inconvenientes, como puede notarse, hacen que explorar las palabras de la ley no sea en absoluto sencillo ni en un plano sincrónico ni diacrónico. Lograr precisión expresiva e interpretativa es una tarea que amerita compromiso y trabajo constante. Esto es, si bien es posible soslayar algunos problemas, como eliminar ambigüedades o vaguedades, las sociedades siempre avanzan y resignifican sus herramientas conceptuales por lo que, los obstáculos que se puedan eliminar en el presente, pueden resurgir, por ejemplo, a través de la textura abierta.

Finalmente, cabe señalar que, si bien este artículo tan solo presenta una pequeña introducción a este tema, es posible ahondar y relevar diversos ejemplos existentes en la legislación que muestren la necesidad de no naturalizar las posibles interpretaciones que dependen de las formulaciones lingüísticas.

\section{Referencias bibliográficas}

Aarnio, Aulis (1987). "Sobre la ambigüedad semántica en a la interpretación jurídica". Doxa: Cuadernos de Filosofía del Derecho, núm. 4 (1987). Universidad de Alicante, pp. 109-117.

Aarnio, Aulis (1990). "La tesis de la única respuesta correcta y el principio regulativo del razonamiento jurídico". Doxa. Cuadernos de Filosofía del Derecho. N. 08 (1990). Universidad de Alicante, pp. 23-38.

Aarnio, Aulis (1991). Lo racional como razonable: un tratado sobre la justificación jurídica. Centro de Estudios Constitucionales.

Álvarez, Graciela (2008). "La enseñanza del discurso jurídico escrito y oral en la carrera de abogacía" Academia. Revista sobre enseñanza del Derecho. Año 6, número 11, pp. 137148 ;

Álvarez, Graciela (2008). La oralidad y su importancia en el Derecho. Rosario: Instituto de Estudios Políticos e Internacionales.

Álvarez, Graciela Esmeralda (2000). "El análisis del discurso desde las distintas perspectivas lingüísticas". Ponencia presentada en el VIII Congreso de la Sociedad Argentina de Lingüística. Mar del Plata. 20/09/2000;

Aseff, Lucía (1998). "La teoría crítica en la Argentina". Doxa. Cuadernos de Filosofía del Derecho. $\mathrm{N}^{\circ}$ 21-II (1998). Universidad de Alicante.

Aseff, Lucía María (2003). Argumentación jurídica y semiosis social. Rosario: Juris.

Austin, John L. (1971) Palabras y acciones. Cómo hacer cosas con palabras. Buenos Aires: Paidós 
Lell, H. M.. Las palabras de la ley y la interpretación normativa. El clásico problema del derecho y el lenguaje. Derecho y Ciencias Sociales. Octubre 2017. No 17. Pgs 164-184 ISNN 1852-2971. Instituto de Cultura Jurídica y Maestría en Sociología Jurídica. FCJ y S. UNLP

Battú, Norma (2016). “Tecnología y movilidad del espacio semántico en el Derecho". Interfolio. Revista del Interescuelas de Filosofía del Derecho. II Interescuelas de Filosofía del Derecho. Octubre de 2016.

Bielsa, Rafael (1954). Los conceptos jurídicos y su terminología. $2^{\circ}$ ed. Buenos Aires: Depalma.

Bobbio, Norberto (1950). "Scienza del diritto e analisi del linguaggio". AAVV. Saggi di critica dellescienze. Torino: De Silva Editora, 1950, pp. 23-66.

Capella, Ramón (1968). El derecho como lenguaje: un análisis lógico. Barcelona: Ariel.

Cárcova, Carlos María (2006). La opacidad del derecho. $2^{\circ}$ ed. Madrid: Trotta.

Cárcova, Carlos María (2009). “Hay una traducción correcta de las normas?”. Revista Electrónica del Instituto de Investigaciones "Ambrosio L. Gioja" - Año III, Número 4, 2009 , pp. 35-42

Carrió, Genaro (1971). Algunas palabras sobre las palabras de la ley. Buenos Aires: Abeledo Perrot.

Carrió, Genaro (2008). Sobre los límites del lenguaje normativo. Buenos Aires: Astrea.

Carrió, Genaro R. (1990/1994) Notas sobre Derecho y lenguaje.4 ed. $1^{\circ}$ reimp. Buenos Aires: AbeledoPerrot: 1990/1994.

Casagrande, Agustín Elías (2011). "El discurso jurídico: aportes metodológicos para un análisis semiótico del derecho" en Revista Derecho y Ciencias Sociales. Abril de 2011. N ${ }^{\circ}$ 4. Instituto de Cultura Jurídica y Maestría en Sociología Jurídica. FCJyS, UNLP, pp. 204224.

CiuroCaldani, Miguel Ángel (2009). "El verbo en el antecedente de la norma jurídica (un aporte a la 'Jurislingüística' con especial referencia a la lengua española)". Revista del Centro de Investigaciones en Filosofía Jurídica y Filosofía Social. Vol. 32.

CiuroCaldani, Miguel Ángel (2011a) "La modificación de las referencias jurídicas adverbiales en una nueva era. Para la "Jurilingüistica" del adverbio" Investigación y Docencia. Vol. 44 (2011). Centro de Investigaciones de Filosofía Jurídica y Filosofía Social, Facultad de Derecho. UNR, 55-77

CiuroCaldani, Miguel Ángel (2011b). "Dos nuevos aportes a la jurilingüística" Investigación y Docencia. Vol. 44 (2011). Centro de Investigaciones de Filosofía Jurídica y Filosofía Social, Facultad de Derecho. UNR, pp. 23-54

Conte, Amadeo (2000). "Normatividad y performatividad". Alarcón Cabrera, Carlos (ed.). Fenomenología, semiótica y derecho. Sevilla: MAD, pp.107-123.

Cornu, Gérard (2005)Linguistiquejuridique. $3^{\circ}$ ed. París: Montchrestien.

Cucatto, Mariana (2012). "La "conexión" en las sentencias penales de primera instancia. Una propuesta desde la Lingüística Cognitiva". Boletín de Lingüística. Vol. XXIV. Caracas, 2012, pp. 54-77

Cucatto, Mariana (2013). "El lenguaje jurídico y su "desconexión" con el lector especialista. El caso de "a mayor abundamiento" Letras de Hoje. Vol. 48. Porto Alegre, 2013, pp. $127-138$

Del Carril, Enrique (2007). El lenguaje de los jueces. Criterios para la delimitación de significados lingüísticos en el razonamiento judicial. Buenos Aires: Ad-Hoc 
Lell, H. M.. Las palabras de la ley y la interpretación normativa. El clásico problema del derecho y el lenguaje. Derecho y Ciencias Sociales. Octubre 2017. No 17. Pgs 164-184 ISNN 1852-2971. Instituto de Cultura Jurídica y Maestría en Sociología Jurídica. FCJ y S. UNLP

Duarte, Carles y Martínez, Anna (1995) El lenguaje jurídico. Buenos Aires: A-Z editora.

Dworkin, Ronald (1988). El imperio de la justicia. Barcelona: Gedisa, 1988.

Endicott, Timothy (2002). "Herbert Hart y el aguijón semántico". Navarro, Pablo y Redondo. María Cristina (comp.). La relevancia del derecho. Ensayos de filosofía jurídica, moral y política. Barcelona: Gedisa, 2002.

Entelman, Ricardo (1982). El discurso jurídico. Buenos Aires: Hachette.

Gałuskina, Ksenia (2012). “Jurilinguistique: du langage spécialisé vers la linguistique de spécialité” RomanicaCracoviensia. Vol. 11. Kraków, pp. 146-153.

García Marcos, Francisco J. (2004) "Lingüística y Derecho". ELUA. Estudios de Lingüística. N. 18. Universidad de Alicante. Departamento de Filología Española, Lingüística General y Teoría de la Literatura, pp. 59-86.

Ghibourg, R., Ghigliani, A., y Guarinoni, R. (1986) Introducción al conocimiento científico. Buenos Aires: Eudeba.

Gómez, Astrid y Bruera, Olga María (1984/2000). Análisis del lenguaje jurídico. $2^{\circ}$ ed. $5^{\circ}$ reimp. Buenos Aires: Editorial de Belgrano.

Guarinoni, Ricardo V. (2006) Derecho, lenguaje y lógica: ensayos de filosofía del derecho. Buenos Aires: LexisNexis.

Guibourg, Ricardo A. (2002) Provocaciones en torno del Derecho. Buenos Aires: Eudeba, 2002

Guibourg, Ricardo A. (2011) "La interpretación del derecho desde el punto de vista analítico". Alarcón Cabrera, Carlos y Vigo, Rodolfo Luis (coord.). Interpretación y argumentación jurídica. Problemas y perspectivas actuales. Buenos Aires/Madrid/Barcelona: Asociación Argentina de Filosofía del Derecho, Sociedad Española de Filosofía Jurídica y Política y Marcial Pons, pp. 227-251

Habermas, Jürgen (2005). Facticidad y validez. Sobre el derecho y el Estado democrático de derecho en términos de teoría del discurso. $4^{\circ}$ ed. Madrid: Trotta.

Hernández, Carlos Arturo (2009). "Lenguaje, derecho y razonamiento jurídico". Ortega Gomero, Santiago (eds.). Interpretación y razonamiento jurídico. Lima: ARA editores, pp. 441-474.

Iturralde Sesma, Victoria (2014). Interpretación literal y significación convencional. Una reflexión sobre los límites de la interpretación jurídica. Madrid/Barcelona/Buenos Aires/São Paulo: Marcial Pons.

Kalinowski, Georges (1985). SémiotiqueetPhilosophie. París/Amsterdam :ÉditionsHadèsBenjamins.

Legendre, Pierre, Entelman, Ricardo, Kozicki, Enrique, Abraham, Tomás, Marí, Enrique, Le Roy, Etienne y Vezzetti, Hugo (1982). El discurso jurídico. Perspectiva psicoanalítica y otros abordajes epistemológicos. Ed. Hachette.

López Hernández, José (2005). "Las normas jurídicas como actos ilocutivos: concepto y clases". Anuario de Derechos Humanos. Nueva Época. Vol. 6, pp. 455-509.

Luque Durán, Juan de Dios (2004). "Características del lenguaje y del léxico”. Aspectos universales y particulares del léxico de las lenguas del mundo. Estudios de Lingüística del Español. (Vol. 21), 2004, pp. 15-36. 
Lell, H. M.. Las palabras de la ley y la interpretación normativa. El clásico problema del derecho y el lenguaje. Derecho y Ciencias Sociales. Octubre 2017. No 17. Pgs 164-184 ISNN 1852-2971. Instituto de Cultura Jurídica y Maestría en Sociología Jurídica. FCJ y S. UNLP

Marmor, Andrei (2001). "Semántica, realismo y derecho natural”. Interpretación y teoría del derecho. Barcelona: Gedisa.

Massini Correas, Carlos Ignacio (1988). "Derecho, pensamiento y lenguaje". Sapientia. Vol XLVIII. Buenos Aires, pp. 139-152.

MassiniCorreas, Carlos Ignacio (1993). "Lenguaje de las normas y Derecho Natural. Consideraciones sobre Georges Kalinowski y la semántica normativa". Anuario de Filosofía del Derecho. X (1993), pp. 325-345.

Mendonca, Daniel (2000). Las claves del derecho. Madrid: Gedisa.

Moore, Michael S. (2001). "Constitutional interpretation and aspirations to a good society. Justifying the natural law theory of constitutional interpretation" Fordham Law Review. Vol 69, Issue 5.

Moore, Michael S. (s/d) "Interpretación constitucional y aspiración a una sociedad buena. Una justificación de la teoría jusnaturalista de la interpretación constitucional”. Pilar Zambrano (trad.).

Narvaja de Arnoux, Elvira (2006). Análisis del discurso. Modos de abordar materiales de archivo. Buenos Aires: Santiago Arcos.

Olivecrona, Karl (2010). Lenguaje jurídico y realidad. $8^{\circ}$ reimpresión, México D.F., Distribuciones Fontamara S.A.

Pardo, María Laura (1992). Derecho y Lingüística. Cómo se juzga con palabras. $2^{\circ}$ edición corregida y aumentada. Buenos Aires: Nueva Visión.

RAE (2014). "Vital". Diccionario de la Lengua Española. Disponible en http://dle.rae.es/?id=bwCD3eL. Visitado el 28/02/2017.

Ruiz, Alicia (2003). "El derecho como discurso y como juego". Revista Jurídica Universidad Interamericana de Puerto Rico. Septiembre-Diciembre.

Ruiz, Alicia (s/d). “Aspectos ideológicos del discurso jurídico. (Desde una teoría crítica del Derecho)" en AAVV. Materiales para una teoría crítica del Derecho. Buenos Aires: Abeledo-Perrot;

Saussure, Ferdinand de (1945). Curso de lingüística general. Publicado por Charles Bally y Albert Sechehaye con la colaboración de Albert Riedlinger. Amado Alonso (trad.).Buenos Aires: Losada, 1945.

Scavino, Dardo (201). La filosofía actual. Pensar sin certezas. $3^{\circ}$ edición. Buenos Aires: Paidós, 2010.

Searle, John (1986). Actos de habla. Madrid: Cátedra.

Sourioux, Jean Louis y Lerat, Pierre (1975). Le langage du droit. París: Presses Universitaires de France.

Streck, Lenio Luiz (1999). Hermenêutica jurídica e(m) crise. Uma exploração hermenêutica da construção do Direito. Porto Alegre: Livraria do Advogado editora.

Streck, Lenio Luiz (2008). Hermenéutica jurídica. Estudios de teoría del Derecho. Lima: ARA editores.

Vasilachis de Gialdino, Irene (2013). Discurso científico, político, jurídico y de resistencia. Análisis lingüístico e investigación cualitativa. Barcelona: Gedisa. 
Lell, H. M.. Las palabras de la ley y la interpretación normativa. El clásico problema del derecho y el lenguaje. Derecho y Ciencias Sociales. Octubre 2017. No 17. Pgs 164-184 ISNN 1852-2971. Instituto de Cultura Jurídica y Maestría en Sociología Jurídica. FCJ y S. UNLP

Vernengo, Roberto (1994a). La interpretación literal de la ley. $2^{\circ}$ ed. Ampliada. Buenos Aires: AbeledoPerrot

Vernengo, Roberto (1994b). "El lenguaje del derecho y el discurso normativo". Anuario de Filosofía Jurídica y Social. Buenos Aires: Asociación Argentina de Filosofía del Derecho.

Viola, Francesco y Zaccaría, Giuseppe (2007). Derecho e interpretación. Elementos de teoría hermenéutica del derecho. Ana Cebeira, Aurelio de Prada y Aurelia Richart (trads.). Madrid: Dykinson.

von Wright, Georg Heinrik (1971). Norma y Acción. Una investigación lógica. Pedro García Ferrero (trad.). Madrid: Tecnos.

Wróblewski, Jerzy (1985/1988). Constitución y teoría general de la interpretación jurídica. Arantxa Azurza (trad.). $1^{\circ}$ reimp. Madrid: Civitas, 1985/1988

Wróblewski, Jerzy (1989). "Los lenguajes del discurso jurídico". Cuadernos del Instituto de Investigaciones Jurídicas. Sobre el Derecho como discurso. México D.F.: UNAM, pp. 357-380.

Zambrano, Pilar (2009). La inevitable creatividad en la interpretación jurídica. Una aproximación iusfilosófica a la tesis de la discrecionalidad. México: Universidad Nacional Autónoma de México.

Zambrano, Pilar (2009b). "El Derecho como práctica y como discurso. La perspectiva de la persona como garantía de objetividad y razonabilidad en la interpretación" 